\title{
Review
}

\section{Impact of fungal drug transporters on fungicide sensitivity, multidrug resistance and virulence $^{\dagger}$}

\author{
Maarten A de Waard, ${ }^{1 *}$ Alan C Andrade, ${ }^{2}$ Keisuke Hayashi, ${ }^{3}$ Henk-jan Schoonbeek, ${ }^{4}$ \\ loannis Stergiopoulos ${ }^{1}$ and Lute-Harm Zwiers ${ }^{1}$ \\ ${ }^{1}$ Laboratory of Phytopathology, Wageningen University, Binnenhaven 5, NL-6709 PD Wageningen, The Netherlands \\ ${ }^{2}$ Embrapa Recursos Genéticos e Biotecnologia, Parque Estação Biológica, Final Avenue W/5 Norte, Brasilia DF, Brazil \\ ${ }^{3}$ Ube Research Laboratory, Ube Industries, Ltd, 1978-5 Kogushi, Ube, Yamaguchi, Japan \\ ${ }^{4}$ Department of Plant Biology, University of Fribourg, Rue Albert Gockel 3, CH-1700 Fribourg, Switzerland
}

\begin{abstract}
Drug transporters are membrane proteins that provide protection for organisms against natural toxic products and fungicides. In plant pathogens, drug transporters function in baseline sensitivity to fungicides, multidrug resistance (MDR) and virulence on host plants. This paper describes drug transporters of the filamentous fungi Aspergillus nidulans (Eidam) Winter, Botrytis cinerea Pers and Mycosphaerella graminicola (Fückel) Schroter that function in fungicide sensitivity and resistance. The fungi possess ATP-binding cassette (ABC) drug transporters that mediate MDR to fungicides in laboratory mutants. Similar mutants are not pronounced in field resistance to most classes of fungicide but may play a role in resistance to azoles. MDR may also explain historical cases of resistance to aromatic hydrocarbon fungicides and dodine. In clinical situations, MDR development in Candida albicans (Robin) Berkhout mediated by ABC transporters in patients suffering from candidiasis is common after prolonged treatment with azoles. Factors that can explain this striking difference between agricultural and clinical situations are discussed. Attention is also paid to the risk of MDR development in plant pathogens in the future. Finally, the paper describes the impact of fungal drug transporters on drug discovery.

(C) 2006 Society of Chemical Industry
\end{abstract}

Keywords: ABC transporters; ATP-binding cassette transporters; fungicides; multidrug resistance; Aspergillus nidulans; Botrytis cinerea; Mycosphaerella graminicola

\section{INTRODUCTION}

During evolution, fungi evolved mechanisms of insensitivity or resistance to protect themselves against a wide variety of toxic compounds. The latter can be natural toxins such as antibiotics produced by microorganisms in their living environment, or plant defence products, particularly relevant for plant pathogens. In addition, the advent of chemical control of plant diseases and mammalian mycoses challenges fungi to a constantly increasing number of synthetic antifungal compounds (drugs, fungicides and antimycotics). Fungi may also need to protect themselves from toxicants of endogenous origin such as antibiotics and mycotoxins that give the producing organism a competitive advantage in its ecological habitat.
Mechanisms of insensitivity or resistance to fungitoxic compounds can relate to qualitative factors such as the absence or presence of a sensitive target site or to quantitative factors such as uptake, transport, storage and metabolism. A quantitative factor involved in sensitivity to natural toxic products and fungicides is drug transporters located in the membranes of fungi. ${ }^{1,2}$ Drug transporters in plasma membranes have the potency to secrete antifungal compounds back into the outer environment. In this way, drug transporters prevent the accumulation of compounds up to fungitoxic concentrations at their target site inside mycelial cells and hence prevent or reduce their toxic action. ATP-binding cassette (ABC) transporters are the most important drug transporters involved

\footnotetext{
* Correspondence to: Maarten A de Waard, Laboratory of Phytopathology, Wageningen University, PO Box 8025, NL-6700 EE Wageningen, The Netherlands

E-mail: maarten.dewaard@wur.nl

${ }^{\dagger}$ Dedicated to our dear friend Giovanni Del Sorbo (University of Naples, Italy) who passed away on 12 October 2004. This article is based on a paper presented at the Meeting of the Research Committee on Fungicide Resistance of the Phytopathological Society of Japan organised by Hideo Ishii and held on 28 March 2005 at Shizuoka City, Japan.
}

(Received 5 July 2005; revised version received 28 September 2005; accepted 28 September 2005) 
in the protection of fungi against antifungals. ${ }^{2}$ The first fungal $\mathrm{ABC}$ transporter characterised was PDR5 from Saccharomyces cerevisiae Meyer ex Hansen. ${ }^{3}$ The protein is a classical multidrug transporter and can confer resistance to many unrelated toxicants. ${ }^{4}$ Readers interested in an inventory of ABC proteins in this organism and the diverse cellular functions revealed are referred to an overview by Bauer et al. ${ }^{5}$

The goal of this paper is to describe the physiological functions of ABC transporters identified in the model fungus Aspergillus nidulans (Eidam) Winter and in the plant pathogens Botrytis cinerea Pers and Mycosphaerella graminicola (Fückel) Schröter. In this context the paper focuses on the ability of drug transporters to provide protection of fungi against antibiotics, plant defence compounds and fungicides, their role in multidrug resistance (MDR) and their function in virulence on host plants. The paper also describes ABC transporters from Candida species, since the significance of MDR development in the treatment of mycoses under clinical situations is more severe than in agriculture. Potential factors contributing to this difference are discussed.

\section{ABC TRANSPORTERS}

$\mathrm{ABC}$ transporter proteins comprise one of the largest families of transport proteins known to date, operating in a wide variety of organisms from bacteria to man. ${ }^{6}$ The proteins are located in the outer plasma membrane or in membranes of intracellular compartments, such as the vacuoles, endoplasmatic reticulum, peroxisomes and mitochondria, and are capable of transporting a wide variety of agents, ranging from ions to macromolecules, against a concentration gradient. ${ }^{2,7,8}$ The energy needed for transport is provided by the hydrolysis of ATP and, for this reason, ABC transporters are characterised as primary active transport systems (Fig. 1A). ABC transporters were originally described in the literature as P-glycoproteins and are also known as PDR (pleiotropic drug resistance) proteins or MDR proteins. ABC transporters became well known in the 1990s because of their vital role in multidrug resistance of human tumours, resulting in the simultaneous loss in activity of multiple unrelated anticancer drugs. At present, MDR is also a serious threat to loss in activity of drugs used in medical treatment against human pathogens. ${ }^{9-11}$

The structural unit of a eukaryotic ABC transporter is most commonly composed of two homologous halves each containing six transmembrane domains (TMDs) and a conserved nucleotide-binding fold $(\mathrm{NBF})$. The NBFs of ABC transporters are located in the cytoplasm. They are distinguished by the presence of highly conserved amino acid sequences, called the Walker A (G-(X)4-G-K-(T)-(X)6-I/V) and Walker B (R/K-(X)3-G-(X)3-L-(hydrophobic)4-D) motifs, and the ABC signature (L-S-G-G-(X)3-R-hydrophobic$\mathrm{X}$-hydrophobic-A). ${ }^{12}$ The catalytic activity of these sites with respect to coupling and hydrolysis of ATP
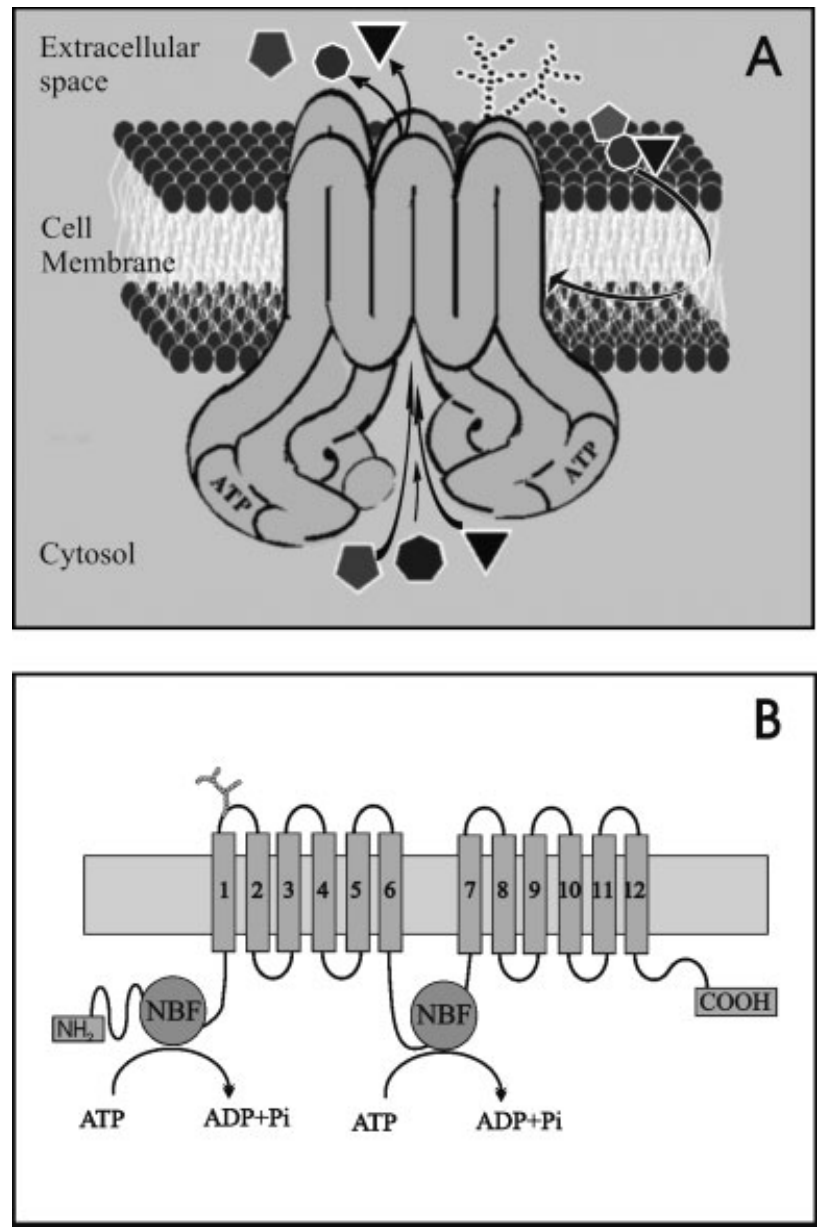

Figure 1. Schematic representation of $(A)$ a three-dimensional model of an ATP-binding cassette (ABC) protein in a lipid bilayer membrane and $(\mathrm{B})$ a two-dimensional model of a transporter with pleiotropic drug resistance (PDR) topology showing the two homologous halves each comprising a nucleotide-binding fold (NBF) and six transmembrane domains.

provides the energy necessary for the transport of substrates. The TMDs of ABC proteins are less conserved than the NBFs. They might form a pore across the lipid bilayer of membranes and are known to play a role in determining the substrate specificity of the transporters. For instance, in the human MDR1 protein, TMDs 4, 5, 6, 10, 11 and 12 and the extracellular loops connecting them are thought to be linked with substrate binding and transport. ${ }^{13}$ Binding of substrates to substrate-binding sites of transporters supposedly triggers ATP hydrolysis and drug transport.

ABC transporters can be classified into different clusters based on their topology. ${ }^{2}$ The majority of the eukaryotic proteins have a $\left[\mathrm{TMD}_{6}-\mathrm{NBF}\right]_{2}$ (MDRtype transporter) or an $\left[\mathrm{NBF}-\mathrm{TMD}_{6}\right]_{2}$ topology (PDR-type topology; Fig. 1B). However, half-sized transporters with a single $\mathrm{TMD}_{6}-\mathrm{NBF}$ or NBF-TMD 6 configuration have also been described and are assumed to function after dimerisation. ${ }^{14}$ Multidrug resistance-related proteins (MRPs) are ABC transporters with a $\mathrm{TMD}_{\mathrm{n}}\left[\mathrm{TMD}_{6}-\mathrm{NBF}\right]_{2}$ topology. They are characterised by the presence of an additional 
transmembrane-spanning domain of approximately 200 amino acids at the $N$-terminus of the protein and by the presence of a putative 'regulatory' (R) or 'connector' domain between the two homologue halves, thought to act in the regulation of the protein. Representatives of this group of transporters have been identified as glutathione $S$-conjugate pumps involved in cellular detoxification and other processes.

ABC transporters include both uptake and efflux systems. In general, they exhibit broad substrate specificity, although transporters with specific substrates also occur. The broad range of substrates for these proteins includes alkaloids, lipids, peptides, steroids, sterols, terpenoids, flavonoids, sugars, inorganic anions and heavy metal chelates. Synthetic compounds such as fungicides, anticancer drugs and other therapeutic or disease control agents have also been described. ${ }^{2,7}$ Most of these compounds have a positive charge at physiological $\mathrm{pH}$, are of hydrophobic nature and enter the cells through passive diffusion. ${ }^{15}$ The way these compounds are perceived and transported is not yet fully understood and several models have been proposed. Perception may be the consequence of non-specific stress, since the compounds alter the biophysical properties of membranes. Alternatively, drug sensor proteins can be involved that bind structurally unrelated compounds. Such proteins have been demonstrated in bacteria. ${ }^{16}$ It may not be excluded that drug transporter proteins themselves can also act as receptor proteins. One of these effects probably triggers a signalling pathway resulting in fast expression of $\mathrm{ABC}$ transporter genes and subsequently drug efflux activity (Fig. 2). ${ }^{17-19}$ Early

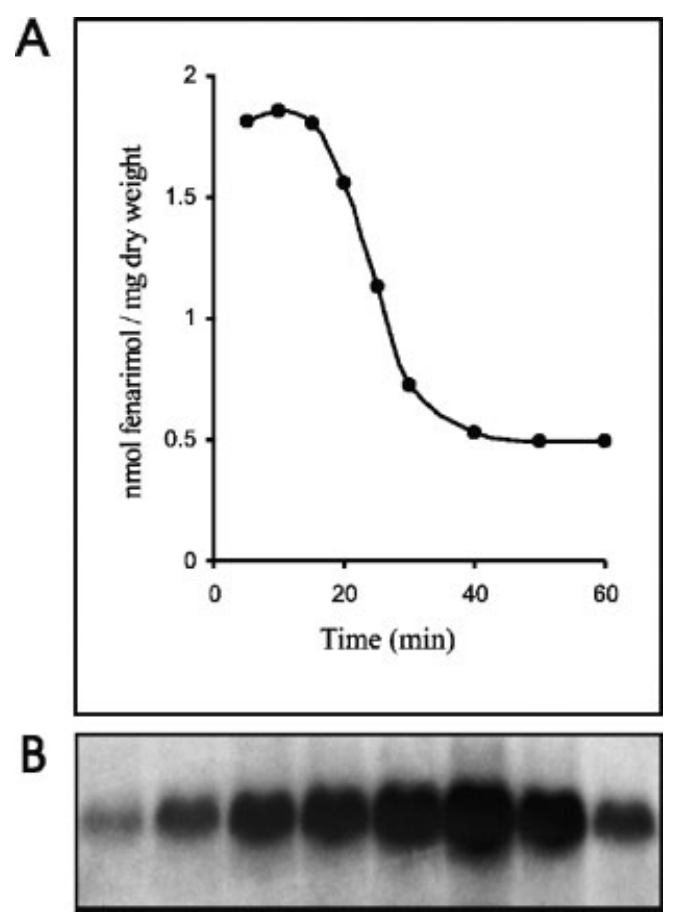

Figure 2. (A) Time-course efflux activity of the azole fungicide fenarimol from germlings of Aspergillus nidulans and (B) time-course induction of expression of atrB upon treatment of germlings with the azole fungicide imazalil. ${ }^{17,19}$ transport models suggest that $\mathrm{ABC}$ proteins act as 'biological pumps' interacting directly with their substrates for their removal from the cytoplasm. However, recent studies indicate that detection and excretion of toxic agents take place at the membrane level before toxic concentrations can build up in the cytoplasm. In this case, drugs are removed directly from the membranes into the extracellular space and therefore ABC transporters are characterised as 'hydrophobic membrane vacuum cleaners'. ${ }^{15}$ A third model suggests that ABC transporters have a flippase activity, translocating drugs from the inner leaflet of the lipid membrane bilayer to the outer one and subsequently releasing them into the outer environment. ${ }^{20}$

In silico analysis of the $S$. cerevisiae genome identified at least 28 different $\mathrm{ABC}$ transporters. Other genomesequencing programmes reported the presence of 56 ABC proteins in Drosophila melanogaster Meig, 56 in Caenorhabditis elegans (Maupas) Dougherty, 129 in Arabidopsis thaliana Heynhoe and 49 in Homo sapiens L. (http://www.nutrigene.4t.com/humanabc.htm, accessed 28 June 2005). Sequence data suggest that an equally high number of $\mathrm{ABC}$ proteins are present in filamentous fungi. Complete sequencing of the Neurospora crassa Shear \& Dodge, Fusarium graminearum Schwabe, Magnaporthe grisea (Hebert) Barr and $A$. nidulans genomes revealed the presence of 70 , 58, 35 and 49 putative ABC proteins respectively (http://www.broad.mit.edu/annotation/fgi/, accessed 13 September 2005). The function of a limited number of these proteins has been elucidated, but the vast majority of them remain to be investigated.

\section{DRUG TRANSPORTERS IN Aspergillus nidulans}

Several ABC transporter genes from $A$. nidulans have been described. Atr $A$ and $a t r B$ encode proteins with an $\left[\mathrm{NBF}-\mathrm{TMD}_{6}\right]_{2}$ topology, while $\operatorname{atr} C$ and $\operatorname{atr} D$ encode proteins with a $\left[\mathrm{TMD}_{6}-\mathrm{NBF}\right]_{2}$ topology. ${ }^{19,21}$ Expression of these genes is up-regulated by a range of natural and synthetic toxic compounds, such as the secondary plant metabolites pisatin and reserpine, the antibiotic cycloheximide and azole fungicides (also described in the literature as sterol demethylation inhibitors). Heterologous expression of $a t r B$ in an ABC transporter-deficient mutant strain of $S$. cerevisiae showed that yeast transformants carrying this gene are resistant to the antibiotic cycloheximide and a number of other drugs, suggesting a role for atrB in MDR. Functional analysis by gene replacement in $A$. nidulans demonstrated that $a t r B$ is involved in protection against compounds from all major classes of fungicide and natural toxic compounds (Fig. 3A). These include anilinopyrimidine, benzimidazole, phenylpyrrole, phenylpyridylamine, azole and strobilurin fungicides as well as the plant alkaloid camptothecin and the phytoalexin resveratrol. ${ }^{22}$ Disruption of atrD in $A$. nidulans resulted in a phenotype hypersensitive to the antibiotics cycloheximide, the 


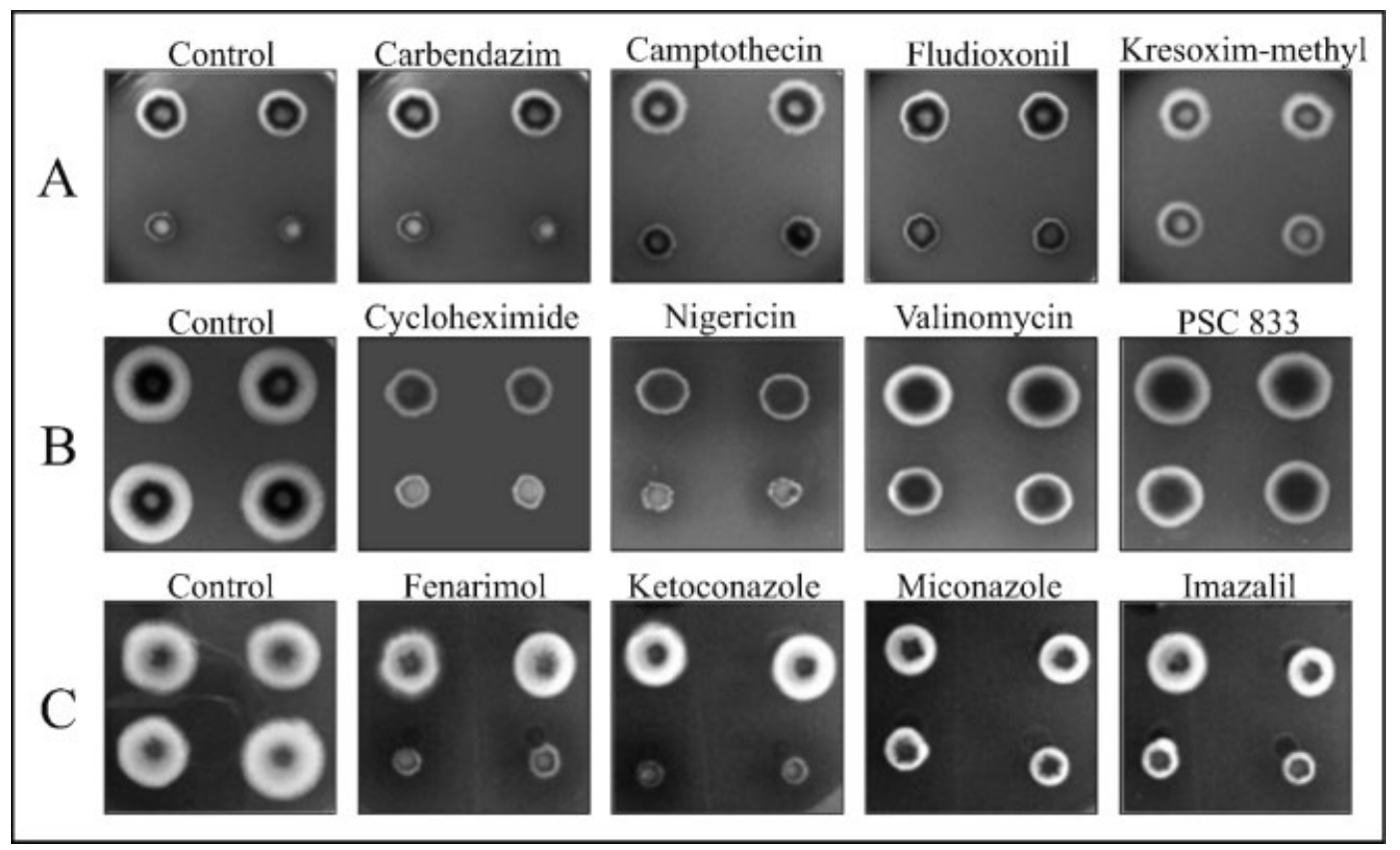

Figure 3. Radial growth of deletion mutants of (A) atrB, (B) atrD and (C) atrG from Aspergillus nidulans on medium amended with antifungals at sublethal concentrations. In each box the two colonies at the top are control transformants with intact atr genes and the two colonies at the bottom are independent deletion mutants ${ }^{21,22}$ (Andrade $A C$, unpublished).

cyclosporin derivative PSC 833, nigericin and valinomycin (Fig. 3B). Recently, we demonstrated that atr $G$ specifically mediates sensitivity to azole fungicides (Fig. 3C). These results show that at least three A. nidulans $\mathrm{ABC}$ transporters play a role in defence against natural toxic products and fungicides.

\section{DRUG TRANSPORTERS IN Botrytis cinerea}

Botrytis cinerea (teleomorph Botryotinia fuckeliana) is the causal agent of the grey mould disease that attacks a wide variety of crop plants and causes serious economic losses. Several ABC transporter genes have been cloned from this fungus. The basal transcript level of these genes varies from undetectable (BcatrC, Bcatrf, BcatrN) to low (BcatrA, BcatrB, BcatrE, Bca$\operatorname{tr} G, B$ catrK) and high (BcatrF, BcatrH, BcatrI). ${ }^{23}$ Treatment with fungicides can increase transcript levels of several of these genes. BcatrB encodes a protein with an $\left[\mathrm{NBF}-\mathrm{TMD}_{6}\right]_{2}$ topology. Increased transcript levels of this gene are observed after short exposure (15-60 min) to antibiotics (e.g. phenazines), phytoalexins (e.g. resveratrol) and phenylpyrrole, anilinopyrimidine and dicarboximide fungicides. ${ }^{23-25}$ Functional analysis by means of gene disruption showed that $\triangle B$ catr $B$ mutants display increased sensitivity to resveratrol, a plant defence compound in grapevine, while virulence tests showed a slight reduction in virulence on detached grapevine leaves as compared with the wild-type control. These results indicate that BcatrB is a virulence factor of $B$. cinerea on grapes by providing protection against resveratrol. ${ }^{24}$ In addition, $\Delta B$ catr $B$ mutants exhibit increased sensitivity to the phenylpyrrole fungicides fenpiclonil and fludioxonil, indicating that drug transporters can play a role in baseline sensitivity to fungicides. Mutants overexpressing BcatrB show decreased sensitivity to phenylpyrroles, suggesting a possible role for BcatrB in fungicide resistance. ${ }^{23} \mathrm{Bcatr} D$ also encodes a protein with an $\left[\mathrm{NBF}-\mathrm{TMD}_{6}\right]_{2}$ topology. This gene exhibits a high level of basal expression in germlings of $B$. cinerea and its transcript level is up-regulated by treatment with azole, dicarboximide and benzimidazole fungicides as well as the antibiotic cycloheximide. ${ }^{26,27}$ A positive correlation between increased transcript levels of BcatrD and resistance to azole fungicides was observed. Replacement mutants of BcatrD exhibit increased sensitivity to several azoles and accumulate relatively high amounts of the azole fungicide oxpoconazole. Likewise, mutants overexpressing $\mathrm{Bca}$ trD show a positive correlation between $B$ catrD expression level and decreased sensitivity to this compound. These results indicate that $B c a t r D$ is a determinant of sensitivity of $B$. cinerea to azoles (Fig. 4). BMR1 $(B$ catrK $)$ encodes a protein with an $\left[\mathrm{NBF}-\mathrm{TMD}_{6}\right]_{2}$ topology. $\triangle B M R 1$ mutants display increased sensitivity to the antibiotic polyoxin and the organophosphorus fungicide iprobenfos, which implies that BMR1 is an additional MDR transporter of this fungus. ${ }^{28}$

\section{DRUG TRANSPORTERS IN Mycosphaerella graminicola}

Five ABC transporter genes ( $M g A t r 1-M g A t r 5)$ have been cloned and sequenced from the plant pathogenic fungus M. graminicola (anamorph Septoria tritici), the causal agent of leaf blotch on wheat. ${ }^{29,30}$ The encoded ABC proteins all exhibit the $\left[\mathrm{NBF}-\mathrm{TMD}_{6}\right]_{2}$ topology. MgAtr1, MgAtr2, MgAtr4 and MgAtr5 display distinct expression profiles when treated with a 


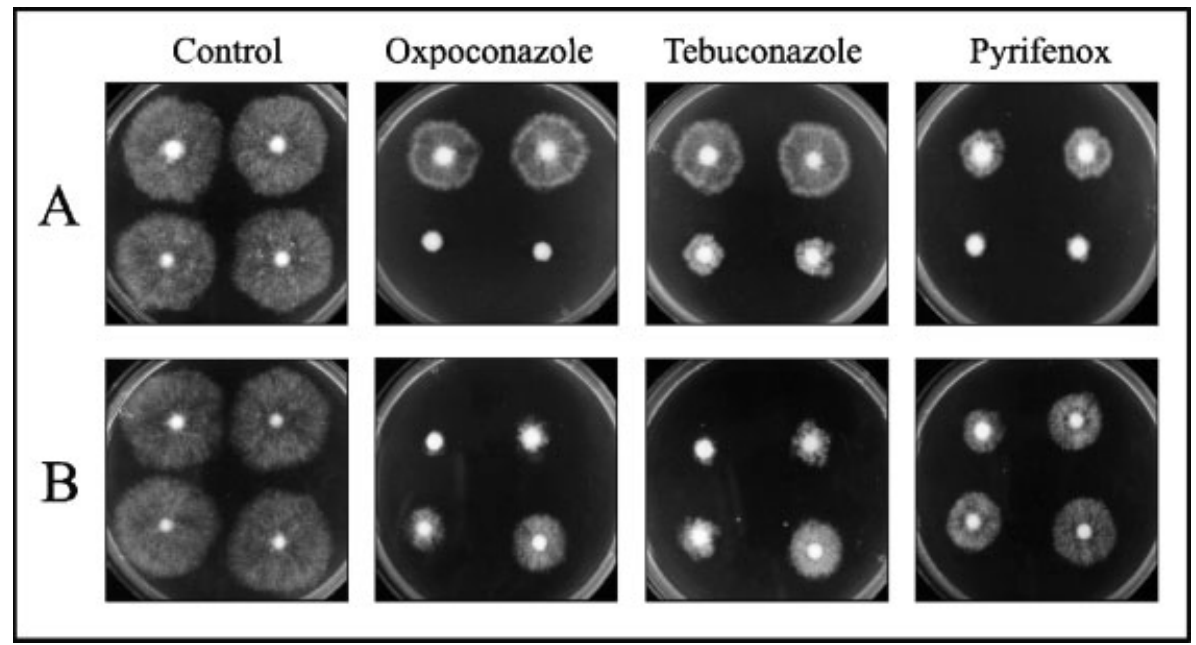

Figure 4. Radial growth of (A) deletion and (B) overexpression mutants of atrD from Botrytis cinerea on medium amended with azole fungicides. (A) In each box the two colonies at the top are control transformants with an intact atrD gene and the two colonies at the bottom are independent deletion mutants. (B) In each box the top-left colony represents the control transformant strain and the top-right, bottom-left and bottom-right colonies represent mutants with low, medium and high degrees of overexpression of atrD respectively. ${ }^{27}$

range of compounds known to be either substrates or inducers of ABC transporters. These include azoles, natural toxic compounds such as the plant defence compounds eugenol and psoralen, and the antibiotics cycloheximide and neomycin. The expression pattern of the genes is also influenced by the morphological state, yeast-like or mycelial, of the fungus. Heterologous expression of $M g A t r 1, M g A t r 2, M g A t r 4$ and $M g A t r 5$ in a strain of $S$. cerevisiae with multiple non-functional ABC transporter genes showed that the products of these genes transport a wide range of chemically unrelated compounds and possess an extensive overlap in substrate specificity (Table 1). ${ }^{31}$ Their substrate range includes synthetic compounds such as azoles and natural toxic compounds such as

Table 1. Sensitivity to antifungals of Saccharomyces cerevisiae strain AD12345678 lacking multiple drug transporter genes and expressing Mycosphaerella graminicola ABC transporter genes MgAtr1, MgAtr2, MgAtr4 or MgAtr5 ${ }^{31}$

\begin{tabular}{lcccc}
\hline Compound & MgAtr1 & MgAtr2 & MgAtr4 & MgAtr5 \\
\hline Fungicides & & & & - \\
Cyproconazole & $+^{\mathrm{a}}$ & + & + & - \\
Propiconazole & + & + & + & - \\
Tebuconazole & + & + & + & - \\
Lipids & & & & - \\
Ergosterol & + & + & + & + \\
Progesterone & + & + & + & + \\
Plant metabolites & & & & - \\
Berberine & + & - & - & - \\
Camptothecin & + & - & & - \\
Antibiotics & + & - & - & - \\
Cycloheximide & + & - & + & - \\
Various & - & + & + & - \\
Diacetoxyscirpenol & + & & & - \\
Rhodamine 6G & - & & & - \\
\hline
\end{tabular}

a The symbols ' + ' and '-' indicate respectively decreased and unaltered sensitivity to antifungals as compared with the pYes2transformed control strain. the plant metabolites berberine and camptothecin and the mycotoxin diacetoxyscirpenol.

The role of $M g A t r 1-M g A t r 5$ in sensitivity to the azole fungicide cyproconazole was studied by expression analysis in laboratory isolates with decreased sensitivity to that fungicide. One of the laboratory mutants possessed a constitutive overexpression of $M g A t r 1$, and $M g A t r 1$ disruptants of this mutant were hypersensitive to cyproconazole (Fig. 5), suggesting that overexpression of $M g A t r 1$ could also be relevant in reduced sensitivity of field isolates. ${ }^{32}$ The function of $M g A t r 1-M g A t r 5$ in virulence of $M$. graminicola on wheat was investigated with knockout mutants. ${ }^{33}$ $\triangle M g A t r 4$ mutants displayed reduced virulence as compared with the wild-type control strain. Northern analysis on RNA isolated from wheat infected with the wild-type isolate and the $\Delta M g A t r 4$ mutant, as well as microscopical analysis, showed a low buildup of biomass of the $\Delta M g A t r 4$ mutant on wheat (Fig. 6). These findings indicate a role for this protein in virulence. ${ }^{33}$ Analysis of the transformants also showed that $\triangle M g A t r 5$ mutants have a small increase in sensitivity to the putative wheat defence compound resorcinol, suggesting a role for this transporter during pathogenesis. ${ }^{31}$ No further phenotypes were observed for any of the mutants and compounds tested. This could be due to redundancy of ABC transporters with a similar substrate range. Thus the possibility that some of these transporters are involved in protection against natural and synthetic toxic compounds cannot be excluded.

\section{DRUG TRANSPORTERS IN Candida albicans}

Candida albicans is an opportunistic pathogen important in humans and the major cause of oropharyngeal candidiasis in immunodepressed patients. The azole fungicide fluconazole has been the most commonly used fungicide in the treatment of the disease. ${ }^{34}$ 


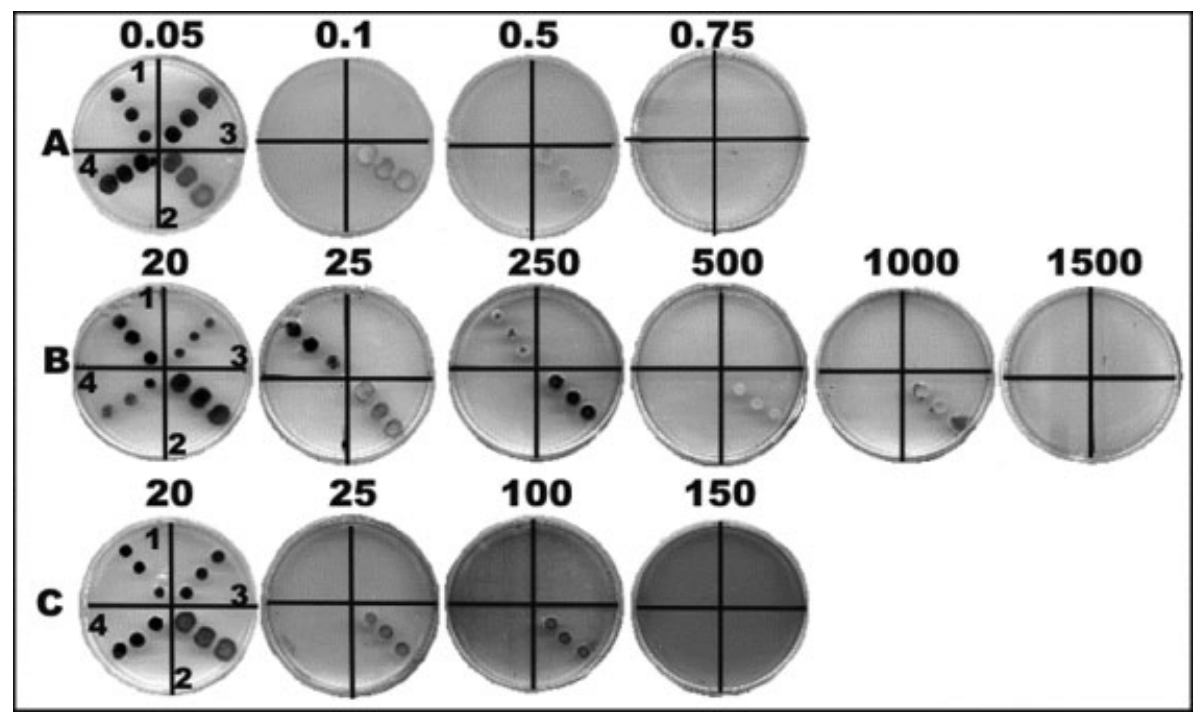

Figure 5. Growth of Mycosphaerella graminicola wild-type strain (quadrant 1), a laboratory-generated azole-resistant strain (quadrant 2) and two independent MgAtr1 knockout mutants of a laboratory-generated azole-resistant strain (quadrants 3 and 4) on medium amended with (A) the azole fungicide cyproconazole, (B) cycloheximide and (C) rhodamine $6 \mathrm{G}^{32}$
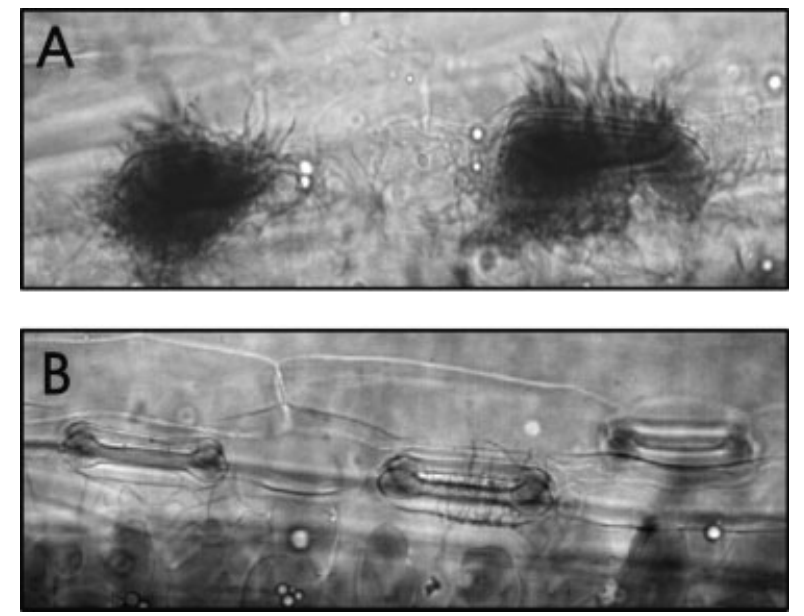

Figure 6. Comparison of virulence of a wild-type and MgAtr4 disruption mutants of Mycosphaerella graminicola on wheat seedling 17 days post-inoculation. (A) Wild-type strain showing dense systemic infection of the leaf apoplast and abundant fungal biomass in substomatal cavities. (B) Mutant strain showing limited intercellular growth in the apoplast and hardly any fungal biomass in stomatal cavities. ${ }^{33}$

Other azoles used in the chemotherapy of candidiasis are itraconazole and ketoconazole. ABC transporters implicated in azole sensitivity and resistance in C. albicans are described as $C D R$ genes. $C D R 1$ encodes the best-characterised multidrug transporter. ${ }^{35}$ It has the $\left[\mathrm{NBF}-\mathrm{TMD}_{6}\right]_{2}$ topology, and complementation of a hypersensitive PDR5-deficient mutant of $S$. cerevisiae with $C D R 1$ restores wild-type insensitivity to azoles, cycloheximide and chloramphenicol. Deletion of both CDR1 alleles in C. albicans results in a strain hypersensitive to the same toxicants and to allylamine and morpholine fungicides. ${ }^{9}$ Heterologous expression of CDR2 in the hypersensitive PDR5-deficient mutant of $S$. cerevisiae showed that the same classes of fungicide also act as substrate for CDR2. Deletion of both $C D R 2$ alleles in C. albicans did not cause hypersensitivity to the toxicants. This could only be observed if $C D R 2$ was deleted in a mutant with a CDR1-deficient background, suggesting that overexpression of CDR1 can compensate for loss of CDR2. ${ }^{10}$ Both CDR1 and $C D R 2$ are under the control of the same transcriptional regulator $C A P 1{ }^{36}$

Clinical isolates of $C$. albicans and other Candida species with azole resistance have been described frequently. Most of these isolates were obtained after prolonged use of azoles for treatment of candidiasis, particularly in immunodepressed patients. These isolates show a clear correlation between reduced in vitro sensitivity and clinical failure of disease control despite proper delivery of adequate amounts of fungicide to the site of treatment. The clinical, cellular and molecular factors that contribute to resistance have been reviewed frequently. ${ }^{11,37-39}$ Resistance to azoles in clinical isolates of C. albicans can be mediated by mechanisms such as target site modifications of sterol 14 alpha-demethylase, increased expression of the target site and increased expression of the major facilitator transporter MDR $1 .^{40-42}$ However, a majority of azole-resistant isolates overexpress CDR1 and $C D R 2$ and display increased efflux of azoles. They also exhibit an MDR phenotype, since the isolates are cross-resistant to the unrelated fungicides terbinafine and caspofungin. ${ }^{43}$ Hence distinct mechanisms of resistance may operate simultaneously and these can contribute to a stepwise development of high resistance levels to azoles in C. albicans. ${ }^{39,41}$ Similar phenomena have been described for other pathogenic yeast species such as C. glabrata. $^{37}$

\section{IMPACT OF DRUG TRANSPORTERS ON MDR IN AGRICULTURAL PRACTICE 7.1 Cases of MDR in practice}

In agricultural practice, obvious cases of MDR to fungicides in plant pathogens are restricted. A classical 
example of an MDR phenotype is the cross-resistance in $B$. cinerea and other pathogens to aromatic hydrocarbons (e.g. chloroneb, dicloran, tolclofos-methyl), dicarboximides (e.g. iprodione, procymidone, vinclozolin) and other fungicides. ${ }^{44}$ The levels of resistance to these compounds were so high that failure in disease control occurred. Many putative mechanisms of resistance were suggested for aromatic hydrocarbonand dicarboximide-resistant mutants of $B$. cinerea, but the actual mechanism has never been fully elucidated. At the time that these mechanisms were investigated, MDR based on increased efflux by drug transporters was not yet known, but, based on present knowledge, we suggest that drug transporters may have played a role in these cases of fungicide resistance.

More recently, $B$. cinerea from French vineyards showed MDR phenotypes for various classes of fungicide. AniR2 and AniR3 isolates possessed cross-resistance to anilinopyrimidines (e.g. cyprodinyl, mepanipyrim, pyrimethanil), dicarboximides, phenylpyrroles (e.g. fenpiclonil, fludioxonil) and other fungicides. ${ }^{45}$ AniR3 isolates were also crossresistant to azole fungicides. ${ }^{45}$ Both types of isolate exhibited low resistance levels and seemed to be effectively controlled in practice. Circumstantial evidence indicates that active efflux is involved. ${ }^{46}$ Since BcatrB and BcatrD are described as a true multidrug transporter and an azole transporter respectively, it is possible that these $A B C$ transporters function in the MDR phenotype of AniR2 and AniR3 isolates. ${ }^{23,26,27}$ Since $B$. cinerea has a family of $\mathrm{ABC}$ transporters that are not functionally analysed completely, it is possible that other ABC transporters can also be responsible for MDR of the AniR2 and AniR3 isolates.

In Europe, pathogens of wheat constitute another major target for disease control by fungicides from different classes of compound. Azoles are one of the most important groups, having been applied for at least 20 years. ${ }^{47}$ Two major foliar pathogens are Blumeria graminis Speer f. sp tritici Marchal and M. graminicola. High levels of field resistance in B. graminis $\mathrm{f}$. sp tritici can probably be ascribed to point mutations in the cyp51 gene encoding the target site of azoles. ${ }^{48}$ Field resistance in $M$. graminicola to azole fungicides has not been reported. However, field populations of the pathogen in France and Germany exhibit a more than 100 -fold difference in sensitivity to cyproconazole. ${ }^{49}$ Azole resistance in laboratory mutants can be associated with expression of specific ABC transporter genes, particularly $M g A t r 1 .^{32}$ For that reason, expression of $M g A t r 1-M g A t r 5$ was also studied in the French and German field isolates. No correlation between azole sensitivity and transcript level of any of the $\mathrm{MgAtr}$ genes tested was observed. ${ }^{49}$ Studies with UK isolates showed similar results, although some isolates from a field with a 40 -fold reduction in sensitivity to the azoles epoxiconazole and flusilazole revealed strongly increased transcript levels of $M g A t r 3 .{ }^{50}$ These results suggest that multiple $\mathrm{ABC}$ transporters can contribute to reduced sensitivity to azoles in field isolates of $M$. graminicola. It might be that other types of drug efflux transporter also play a role in reduced sensitivity of field isolates. The full genome of $M$. graminicola was sequenced in 2005 and, as a result, all ABC and MFS drug transporter genes as well as other putative genes in azole resistance can be identified. Screening of their expression by means of microarray analysis may reveal genes that play a more obvious role in resistance than the ones identified so far.

MDR in practice is also described for azole-resistant isolates of Penicillium digitatum (Pers) Sacc. These isolates are cross-resistant to unrelated chemicals and show an up-regulation of gene expression of the ABC transporter gene PMR1.51 Other ABC transporter genes involved in drug resistance in $P$. digitatum have also been described. ${ }^{52}$ The distinct role of these various transporters in MDR still remains to be elucidated.

\subsection{Stepwise evolution of resistance and drug transporters}

Circumstantial evidence for a role of multidrug transporters in fungicide resistance is also provided by the observation of stepwise evolution of resistance in practice and predisposition of fungicide sensitivity by previous selection with unrelated fungicides. Stepwise evolution of fungicide resistance became known after the introduction of azole fungicides. One of the first cases was described for azole sensitivity in Sphaerotheca fuliginea (Schlecht ex Fr) Poll. A stepwise decrease in sensitivity to imazalil and fenarimol over a 3 year period was observed in The Netherlands. ${ }^{53}$ At present the field performance of these compounds in the control of cucumber powdery mildew is low. Similarly, stepwise evolution of decreased sensitivity to fungicides has been described for other mildew pathogens such as $B$. graminis f. sp hordei, $B$. graminis f. sp tritici and the leaf blotch pathogen M. graminicola. ${ }^{47,49,54,55}$ A possible explanation for stepwise evolution of resistance is polygenic resistance related to $\mathrm{ABC}$ transporter genes as described for azole fungicides in vitro in laboratory-generated mutants of $A$. nidulans and Nectria haematococca Berk \& Broome. ${ }^{56,57}$ Ample evidence is provided that azole-resistant mutants of these organisms indeed overexpress multiple ABC transporter genes and/or display reduced accumulation of azoles in the mycelium owing to increased efflux activity. Stepwise development of resistance to azoles related to reduced accumulation of these fungicides was also observed in laboratory-generated mutants of $P$. italicum Wehmer. ${ }^{58,59}$ However, it should be kept in mind that stepwise development of resistance does not necessarily imply multiple ABC transporter genes, since this phenomenon can also be based on a combination of different mechanisms as observed in C. albicans and M. graminicola. $^{32,41}$

\subsection{Predisposition and drug transporters}

Predisposition of fungicide sensitivity by previous selection with unrelated fungicides has been described 
in Venturia inaequalis (Cooke) Winter. ${ }^{60}$ This pathogen developed stepwise resistance to dodine in the USA in the 1960 s. ${ }^{61}$ In $V$. inaequalis, four levels of reduced sensitivity were detected, suggesting the additive action of at least two genes for dodine resistance. ${ }^{62}$ Dodine resistance in $N$. haematococca is determined by four unlinked loci and, in recombinants, these genes have an additive effect on resistance. The presence of resistance genes was correlated with increased efflux activity of dodine or its metabolites from mycelium. ${ }^{63}$ These results suggest that resistance in fungi to dodine is a polygenic trait related to increased drug transporter activity. In the course of these studies on dodine, resistance attention was probably never paid to an MDR phenotype of these resistant isolates. However, in the 1990s, resistance to azoles developed to significantly higher frequencies within dodine-resistant populations than in dodine-sensitive ones. ${ }^{60}$ Recently, isolates of $V$. inaequalis from New York state demonstrated a correlation in sensitivity to azoles and anilinopyrimidines. The correlation was most significant in subpopulations of the pathogen previously treated over 10 years with azoles but not with anilinopyrimidines. Subpopulations differed in azole sensitivity, and it might be that at least one of the genes conferring azole resistance also lowered sensitivity to anilinopyrimidines and that a common resistance mechanism is involved (Köller, personal communication). Predisposition was also described in Uncinula necator (Schw) Burr to the QoI fungicide azoxystrobin in fungal populations with decreased sensitivity to the azole fungicide myclobutanil. ${ }^{64}$ In our view these cases of predisposition to fungicides may represent cases of multidrug resistance in practice. Circumstantial evidence to support this hypothesis is that the degrees of resistance involved are relatively low, which is quite common for resistance mediated by drug transporters. In addition, it is known that laboratory mutants of $A$. nidulans overexpressing the ABC transporter gene $a t r B$ display MDR to azoles, anilinopyrimidines and QoI fungicides. ${ }^{22}$ These observations suggest that a similar overexpression of transporter gene(s) may have happened in the above-mentioned cases of predisposition to fungicides. It is important to investigate predisposition in more detail, since validation of the hypothesis that $\mathrm{ABC}$ transporters are involved in this phenomenon would implicate that drug transporters are more important determinants in fungicide sensitivity and resistance than ever anticipated.

\section{DISCUSSION}

\subsection{MDR in practice}

The main reason for the limited relevance of MDR in agricultural practice is probably that evolution of resistance is dominated by mutants with changed target site modifications. In general, mutants with target site modifications have a decreased affinity for the fungicide and are common for most classes of fungicide (benzimidazoles, carboximides, dicarboximides, QoI fungicides). Populations with a high frequency of such mutants can often be selected within a few years of selection pressure in polycyclic pathogens with a high propagation rate. Other major determinants in rapid evolution of populations composed of such mutants are a high level of resistance associated with these single-gene mutations and a normal fitness as compared with the wild-type isolate. Obviously, such mutant populations will mask subpopulations composed of mutants with low levels of resistance and a fitness penalty.

This reasoning implies that fungicide resistance in plant pathogens based on alternative mechanisms will only become detectable in practice in exceptional cases when resistance based on target site modifications cannot evolve readily. This situation is probably applicable for azole fungicides, since target site modifications in field-resistant isolates have only been described for $B$. graminis f. $\mathrm{sp}$ hordei and $U$. necator but never for other pathogens such as M. graminicola. $^{48,50}$ The underlying reason for this situation is not known, but it might be that target site mutations of CYP51 resulting in azole resistance are lethal or strongly reduce comparative fitness. This hypothesis is corroborated by early findings that the degree of resistance to azoles in laboratory mutants of Cladosporium cucumerinum Ell \& Arthur correlates negatively with virulence and in $A$. nidulans with saprophytic growth. ${ }^{65}$ In view of this situation it is no surprise that multiple mechanisms of resistance to azoles in various fungi have been reported. A mechanism reported for azole-resistant field isolates of $P$. digitatum and $V$. inaequalis is overexpression of CYP51 caused by tandem repeats in its promoter region. ${ }^{66,67}$ Another mechanism that can operate in plant pathogens is increased expression of drug transporters, associated with increased azole efflux and decreased accumulation of these compounds at their target site. Under practical conditions this mechanism has only been reported for azole-resistant isolates of $P$. digitatum (Section 7.1). ${ }^{52}$ Also described in Section 7.1 is circumstantial evidence for a role of this mechanism in particular azole-resistant field isolates of B. cinerea and M. graminicola. This evidence is mainly based on expression analysis. These results should be interpreted with care and one should consider that conclusive evidence in this respect may be difficult to achieve, because multiple resistance mechanisms may operate simultaneously. An additional difficulty in studying azole resistance in $B$. cinerea and $M$. graminicola is their significant phenotypic variability, also with respect to baseline sensitivity to fungicides, and, related to this, the inability to identify the corresponding wild-type mother isolates of azoleresistant field isolates which are required to determine the degree of reduced azole sensitivity.

Azole resistance in the human pathogenic yeast C. albicans evolves readily in patients undergoing 
Table 2. Putative epidemiological and operational factors involved in $A B C$ transporter-mediated resistance development to azole fungicides in plant pathogens and Candida albicans

\begin{tabular}{|c|c|c|}
\hline Factor & Plant pathogens & C. albicans \\
\hline Population size & Large; not limited to a treated field & $\begin{array}{l}\text { Can be restricted to a single patient } \\
\text { undergoing drug therapy }\end{array}$ \\
\hline Duration of life cycle & Days-weeks & Hours \\
\hline $\begin{array}{c}\text { Refugia for survival of wild-type } \\
\text { population during treatment }\end{array}$ & Present & Limited-absent \\
\hline Long-distance mobility of propagules & Possible between fields & More difficult between patients \\
\hline Frequency of application & Limited number of sprays per season & $\begin{array}{l}\text { Long-term treatment regimens for weeks or } \\
\text { months }\end{array}$ \\
\hline Mode of application & $\begin{array}{l}\text { Sprays that allow escape of sensitive } \\
\text { subpopulation }\end{array}$ & $\begin{array}{l}\text { Oral treatment that reduces escape of } \\
\text { sensitive subpopulation }\end{array}$ \\
\hline $\begin{array}{l}\text { Selection of mutants that } \\
\text { compensate for loss of fitness }\end{array}$ & $\begin{array}{l}\text { Not readily possible because periods without } \\
\text { selection allow competition with wild-type } \\
\text { isolates }\end{array}$ & $\begin{array}{l}\text { Possible since elimination of wild-type } \\
\text { population can annul competition }\end{array}$ \\
\hline Multiple attack & $\begin{array}{l}\text { Fungicide mixtures and rotational use of } \\
\text { fungicides with different resistance } \\
\text { mechanisms }\end{array}$ & $\begin{array}{l}\text { Exclusive use of fluconazole for whole } \\
\text { treatment period }\end{array}$ \\
\hline Host & $\begin{array}{l}\text { No host plant conditions known that would } \\
\text { favour MDR }\end{array}$ & $\begin{array}{l}\text { Favoured by absence of immune system in } \\
\text { patients }\end{array}$ \\
\hline
\end{tabular}

antifungal therapy (Section 6). In this context, resistance based on increased expression of ABC transporters is common and an obvious question is why this situation is so different from azole resistance in plant pathogens. In general, the rapid emergence of resistance to azoles in $C$. albicans (including resistance mediated by ABC transporters) is ascribed to the net effect of the (small) pathogen population size and high mutation rate. ${ }^{39}$ The mutation rate in plant pathogens for azole resistance is also high and hence cannot explain the slow resistance development mediated by $\mathrm{ABC}$ transporters in plant pathogens. ${ }^{57} \mathrm{~A}$ major difference between the two groups of pathogens is the population size, being extremely large for many plant pathogens. Therefore we suppose that the large size of plant pathogen populations constitutes a major factor in slow resistance development to azoles in plant pathogens. Additional epidemiological and operational factors possibly involved as well are summarised in Table 2. We suggest that a combination of these factors and the observation that $\mathrm{ABC}$ transporter mutants often possess a fitness penalty in the absence of selection pressure significantly delays the selection of such azole-resistant populations in plant pathogens.

We believe that, in the long run, MDR in plant pathogens will develop more frequently in agriculture. This might be the result of stepwise selection of MDR mutants with higher levels of resistance that can better cope with full application rates of fungicides. This may be relevant for azole sensitivity in pathogens such as M. graminicola. Recent surveys indicate that sensitivity to azoles in populations of this pathogen gradually reduced up to 20 -fold in particular locations in France and Germany. ${ }^{55}$ In 2003 in the UK a field population with a 40-fold reduction in sensitivity to the azoles epoxiconazole and flusilazole was detected. ${ }^{50}$ Such shifts will gradually reduce the performance of azole fungicides, especially that of the weaker members.
In the long run, MDR mutants of plant pathogens may also have a higher chance of restoring normal fitness by compensatory mutations. Compensatory mutations not only occur in yeasts but have also been described for phenylpyrrole-resistant mutants of $A$. nidulans (Fig. 7). ${ }^{68}$ So far, underlying mechanisms related to these mutations are not known.

Possibly, the simultaneous application of fungicides from different chemical classes constitutes an additional risk for MDR development in plant pathogens, since this situation prevents or delays the evolution of mutants with target site modifications but may not be effective against MDR mutants. Multiple attacks by diverse fungicides are common practice in anti-resistance strategies for disease control in major agricultural crops such as banana, cereals, rice and grapevine. These strategies imply the use of fungicide mixtures and rotational use of these compounds. If the hypothesis is valid, it might be that the selection of MDR mutants of $B$. cinerea in French vineyards relates to such a multiple attack by fungicides. It might also be relevant for pathogens such as Mycosphaerella musicola Mulder (banana), M. graminicola (wheat) and Pyricularia oryzae Cavara (rice). This situation might have serious consequences for future disease control with new classes of chemical because of predisposition to new fungicides as described in Section 7.3.

\subsection{Functional analysis of drug transporter genes}

To date, functional analysis of drug transporters has mainly been performed for individual transporter genes, cloned with the help of heterologous probes or PCR using degenerated primers. In future, sequences of fungal genomes will become available in increasing number, which will facilitate the cloning of drug transporter genes more easily. Sequences are usually not helpful to predict the physiological function of 


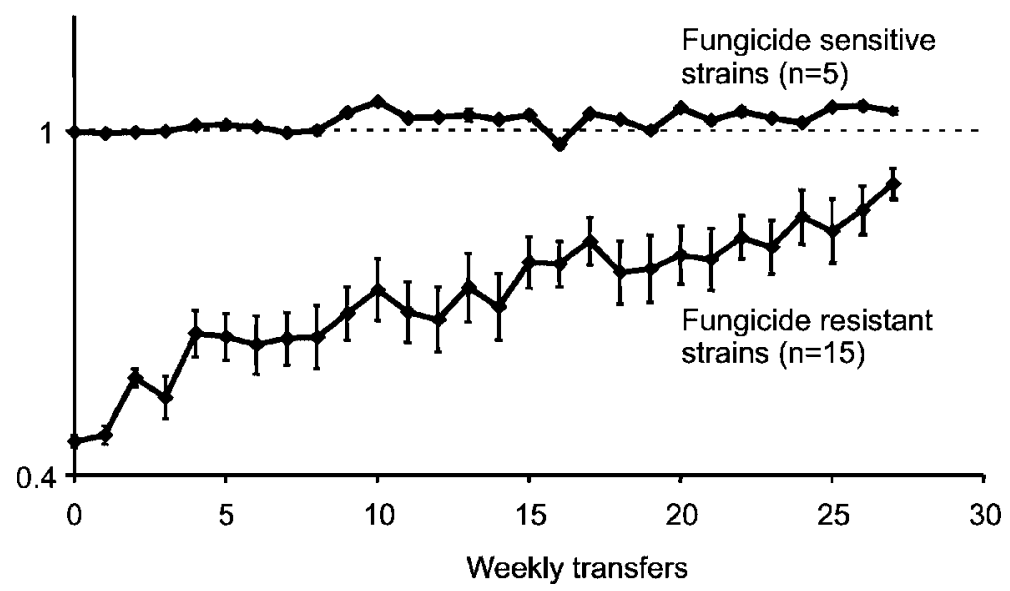

Figure 7. Radial growth rate of a wild-type strain of Aspergillus nidulans and a fludioxonil-resistant mutant relative to that of the wild-type strain upon weekly transfers on minimal medium (without fungicide). Note that fitness loss in the fludioxonil-resistant strain is compensated in time. During transfers the initial degree of fludioxonil resistance was retained. Genetic analysis of a fludioxonil-resistant mutant revealed interactions between three fitness compensatory mutations. ${ }^{68}$

the encoded proteins. However, it might be that the phylogenetic relationship of the proteins may provide some predictive value. This has already been shown for ABC transporters of $A$. nidulans involved in transport of azole fungicides. ${ }^{69}$ It is anticipated that these types of study will identify many more putative ABC transporter genes involved in MDR than have been described so far.

\subsection{Impact of drug transporters on fungicide discovery}

Since drug transporters reduce the activity of fungicides, fungal mutants that lack drug transporters may become fungicide-hypersensitive and can be used as tester strains in fungicide discovery screening programmes. We have constructed a triple knockout mutant of $A$. nidulans with non-functional atrB, $\operatorname{atr} D$ and $\operatorname{atr} G$ genes. The mutant has an increased sensitivity to many unrelated fungicides, antibiotics and to natural antifungal compounds from plants. We propose this mutant as a useful tester strain in high-throughput screening for lead compounds of agricultural fungicides and antimycotics (Fig. 8). ${ }^{70}$ Similar suggestions were made to discover new antimycotics. ${ }^{11}$ Multiple disruption mutants are also useful in structure-activity studies and may be used as a tool to explain why fungi with a sensitive target site have a whole-cell insensitivity to fungicides and cannot be controlled under field conditions. ${ }^{70}$

A rational approach in the search for new antifungals would also be the development of compounds that inhibit $\mathrm{ABC}$ transporters involved in fungicide activity or virulence. These compounds are described in the medical literature as blockers or modulators of $\mathrm{ABC}$ transporters and are tested in human chemotherapy as synergists of drugs or as compounds that annihilate $\mathrm{MDR}$ in cancer cells. ${ }^{71}$ Similarly, such compounds could be developed as synergists of agricultural fungicides or as compounds that

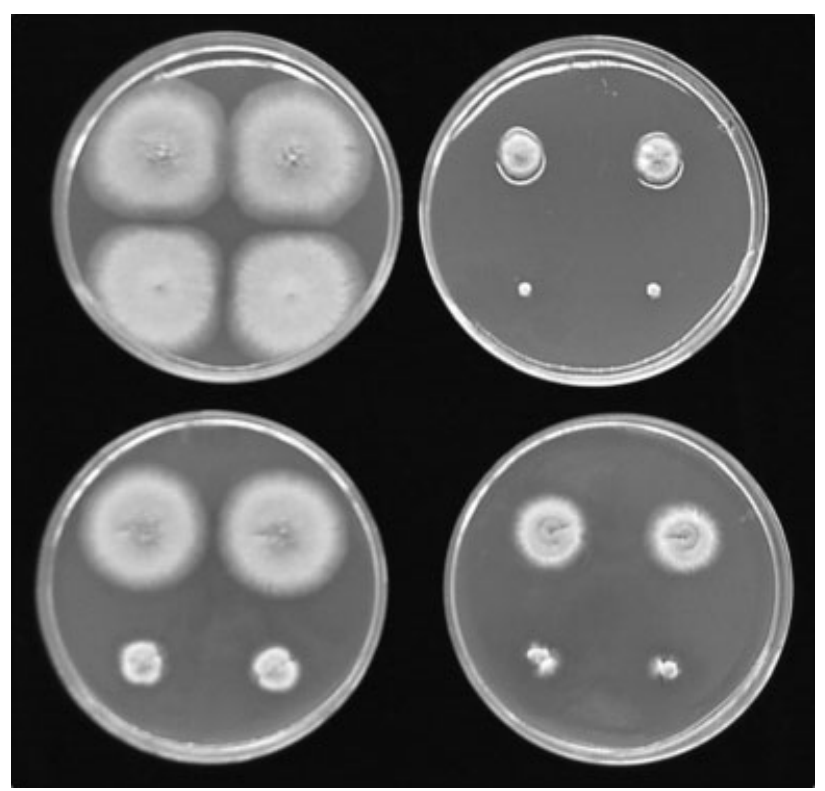

Figure 8. Radial growth of Aspergillus nidulans on (top left) control medium and medium amended with (top right) fludioxonil, (bottom left) nigericine and (bottom right) fenarimol. In each petri dish the two colonies at the top represent control transformant strains and the two colonies at the bottom represent independent mutants with non-functional atrB, atrD and atrG $A B C$ transporter genes.

annul MDR in plant pathogens (Fig. 9). Such compounds have been described. ${ }^{72-74}$ Recently, it was demonstrated that combinations of azole or strobilurin fungicides with a hydroxyflavone derivative shifted fungicide-resistant Pyrenophora tritici-repentis (Died) Dreschler isolates back to normal sensitivity levels and prevented infection of wheat leaves. ${ }^{75}$ The feasibility of developing ABC modulators for use in practice needs to be investigated further.

Another approach would be to develop modulators that inhibit the activity of ABC transporters involved in fungal virulence on host plants. The role of drug transporters in virulence on a range of host 


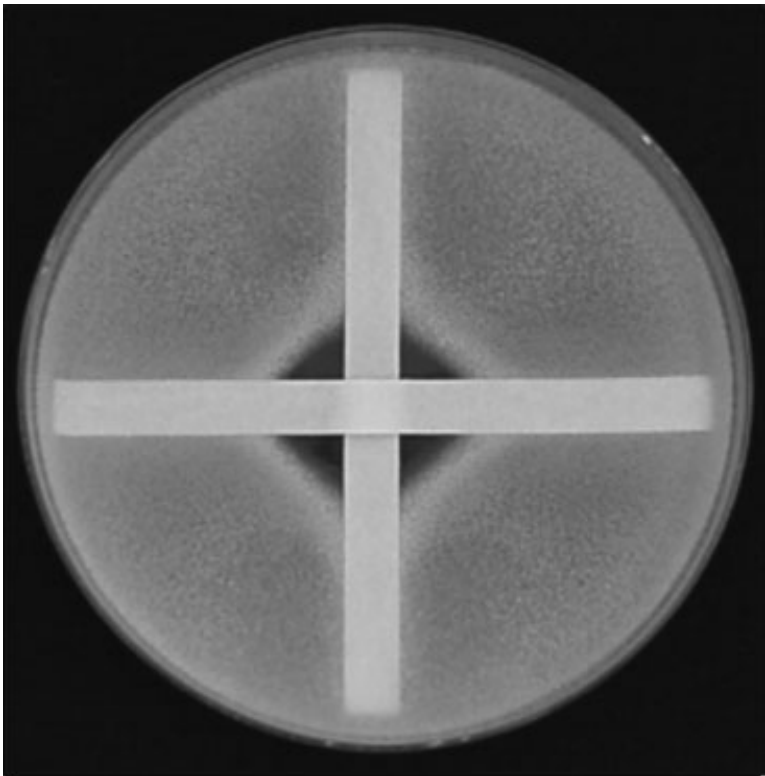

Figure 9. Cross-paper strip experiment showing that chlorpromazine (impregnated in horizontal strip), known as a modulator of $A B C$ transporter activity, can annihilate resistance to the azole fungicide oxpoconazole (impregnated in vertical strip) in a BcatrD overexpression mutant of Botrytis cinerea. ${ }^{74}$

plants has now been demonstrated for ABC and MFS transporters in a range of important plant pathogens. ${ }^{2}$ It is anticipated that this number will increase, especially in pathogens of host plants known to produce phytoalexins. Inhibition of such transporters would enhance accumulation of plant defence compounds in fungal cells and hence exploit the natural defence reaction of host plants. Such compounds do not necessarily need to be fungitoxic in vitro, and hence development of such compounds might result in the discovery of disease control agents that do not have a direct fungitoxic activity. A prerequisite for the discovery of these compounds is, of course, selective activity between the target and the non-target organism. This may be feasible, since modulators used as medical drugs can have a selective activity to cancer cells in humans.

\section{ACKNOWLEDGEMENTS}

The authors are very grateful to Giovanni Del Sorbo for his enthusiastic and pioneering work on the discovery of ABC transporters in $A$. nidulans and $B$. cinerea. They also thank Hans Van Nistelrooy for his skilful assistance from 1980 to 2004 in many experiments, especially on fungicide accumulation in fungi. Ciska Braam, Marco Gielkens, Stephen Goodall, Koen Venema and Tycho Vermeulen provided excellent experimental support to the research as well.

\section{REFERENCES}

1 De Waard MA, Significance of ABC transporters in fungicide sensitivity and resistance. Pestic Sci 51:271-275 (1997).
2 Stergiopoulos I, Zwiers L-H and De Waard MA, Secretion of natural and synthetic toxic compounds from filamentous fungi by membrane transporters of the ATP-binding cassette and major facilitator superfamily. Eur F Plant Pathol 108:719-734 (2002).

3 Balzi E, Wang M, Leterme S, VanDyck L and Goffeau A, PDR5, a novel yeast multidrug resistance conferring transporter controlled by the transcription regulator PDR1. $\mathcal{F}$ Biol Chem 269:2206-2214 (1994).

4 Kolaczkowski M, van der Rest M, Kolaczkowska A, Soumillion JP, Konings WN and Goffeau A, Anticancer drugs, ionophoric peptides, and steroids as substrates of the yeast multidrug transporter Pdr5p. F Biol Chem 271:31 543-31 548 (1996).

5 Bauer $\mathrm{BE}$, Wolfger $\mathrm{H}$ and Kuchler $\mathrm{K}$, Inventory and function of yeast ABC proteins: about sex, stress, pleiotropic drug and heavy metal resistance. Biochim Biophys Acta 1461:217-236 (1999).

6 Higgins CF, ABC transporters: from microorganisms to man. Annu Rev Cell Biol 8:67-113 (1992).

7 Del Sorbo G, Schoonbeek $H$ and De Waard MA, Fungal transporters involved in efflux of natural toxic compounds and fungicides. Fungal Genet Biol 30:1-15 (2000).

8 Theodoulou FL, Plant ABC transporters. Biochim Biophys Acta-Biomembranes 1465:79-103 (2000).

9 Sanglard D, Kuchler K, Ischer F, Pagani JL, Monod M and Bille J, Mechanisms of resistance to azole antifungal agents in Candida albicans isolates from AIDS patients involve specific multidrug transporters. Antimicrob Agents Chemother 39:2378-2386 (1995).

10 Sanglard D, Ischer F, Monod M and Bille J, Cloning of Candida albicans genes conferring resistance to azole antifungal agents: characterization of CDR2, a new multidrug ABC transporter gene. Microbiology 143:405-416 (1997).

11 Skatrud PL, The impact of multiple drug resistance (MDR) proteins on chemotherapy and drug discovery. Prog Drug Res 58:99-131 (2002).

12 Walker JE, Saraste M, Runswick MJ and Gay NJ, Distantly related sequences in the alpha- and beta-subunits of ATP synthase, myosin, kinases and other ATP-requiring enzymes and a common nucleotide binding fold. EMBO f 1:945-951 (1982).

13 Zhang XP, Collins KI and Greenberger LM, Functional evidence that transmembrane 12 and the loop between transmembrane 11 and 12 form part of the drug-binding domain in P-glycoprotein encoded by MDR1. F Biol Chem 270:5441-5448 (1995).

14 Decottignies A and Goffeau A, Complete inventory of the yeast ABC proteins. Nat Genet 15:137-145 (1997).

15 Gottesman MM and Pastan I, Biochemistry of multidrug resistance mediated by the multidrug transporter. Annu Rev Biochem 62:385-427 (1993).

16 Lewis K, Multidrug resistance: versatile drug sensors of bacterial cells. Curr Biol 9:403-407 (1999).

17 De Waard MA and Van Nistelrooy JGM, Mechanism of resistance to fenarimol in Aspergillus nidulans. Pestic Biochem Physiol 10:219-229 (1979).

18 De Waard MA and Van Nistelrooy JGM, An energy dependent efflux mechanism for fenarimol in a wild type strain and fenarimol resistant mutants of Aspergillus nidulans. Pestic Biochem Physiol 13:255-266 (1980).

19 Del Sorbo G, Andrade AC, Van Nistelrooy JG, Van Kan JA, Balzi E and De Waard MA, Multidrug resistance in Aspergillus nidulans involves novel ATP-binding cassette transporters. Mol Gen Genet 254:417-426 (1997).

20 Higgins CF and Gottesman MM, Is the multidrug transporter a flippase? Trends Biochem Sci 17:18-21 (1992).

21 Andrade AC, Van Nistelrooy JGM, Peery RB, Skatrud PL and De Waard MA, The role of ABC transporters from Aspergillus nidulans in protection against cytotoxic agents and in antibiotic production. Mol Gen Genet 263:966-977 (2000). 
22 Andrade AC, Del Sorbo G, Van Nistelrooy JGM and De Waard MA, The ABC transporter AtrB from Aspergillus nidulans mediates resistance to all major classes of fungicides and some natural toxic compounds. Microbiol UK 146:1987-1997 (2000).

23 Vermeulen $T$, Schoonbeek $H$ and De Waard MA, The ABC transporter BcatrB from Botrytis cinerea is a determinant of the phenylpyrrole fungicide fludioxonil. Pest Manag Sci 57:393-402 (2001).

24 Schoonbeek H, Del Sorbo G and De Waard MA, The ABC transporter BcatrB affects the sensitivity of Botrytis cinerea to the phytoalexin resveratrol and the fungicide fenpiclonil. Mol Plant-Microbe Interact 14:562-571 (2001).

25 Schoonbeek H, Raaijmakers JM and De Waard MA, Fungal ABC transporters and microbial interactions in natural environments. Mol Plant-Microbe Interact 15:1165-1172 (2002).

26 Hayashi K, Schoonbeek H, Sugiura H and De Waard MA, Multidrug resistance in Botrytis cinerea associated with decreased accumulation of the azole fungicide oxpoconazole and increased transcription of the $\mathrm{ABC}$ transporter gene BcatrD. Pestic Biochem Physiol 70:168-179 (2001).

27 Hayashi K, Schoonbeek H and De Waard MA, Expression of the ABC transporter BcatrD from Botrytis cinerea reduces sensitivity to sterol demethylation inhibitor fungicides. Pestic Biochem Physiol 73:110-121 (2002).

28 Nakajima M, Suzuki J, Hosaka T, Hibi T and Akutsu K, Functional analysis of an ATP-binding cassette transporter gene in Botrytis cinerea by gene disruption. $\mathcal{F}$ Gen Plant Pathol 67:212-214 (2001).

29 Stergiopoulos I, Gielkens MMC, Goodall SD, Venema K and De Waard MA, Molecular cloning and characterisation of three new ABC transporter encoding genes from the wheat pathogen Mycosphaerella graminicola. Gene 289:141-149 (2002).

30 Zwiers L-H and De Waard MA, Characterization of the ABC transporter genes $M g A t r 1$ and $M g A t r 2$ from the wheat pathogen Mycosphaerella graminicola. Fungal Genet Biol 30:115-125 (2000).

31 Zwiers L-H, Stergiopoulos I, Gielkens MMC, Goodall SD and De Waard MA, ABC transporters of the wheat pathogen Mycosphaerella graminicola function as protectants against biotic and xenobiotic toxic compounds. Mol Genet Genom 269:499-507 (2003)

32 Zwiers L-H, Stergiopoulos I, Van Nistelrooy JGM and De Waard MA, ABC transporters and azole susceptibility in laboratory strains of the wheat pathogen Mycosphaerella graminicola. Antimicrob Agents Chemother 46:3900-3906 (2002).

33 Stergiopoulos I, Zwiers L-H and De Waard MA, The ABC transporter MgAtr4 is a virulence factor of Mycosphaerella graminicola that affects colonisation of substomatal cavities in wheat leaves. Mol Plant-Microbe Interact 16:689-698 (2003).

34 Sanglard D, Ischer F, Monod M and Bille J, Susceptibilities of Candida albicans multidrug transporter mutants to various antifungal agents and other metabolic inhibitors. Antimicrob Agents Chemother 40:2300-2305 (1996).

35 Prasad R, De Wergifosse P, Goffeau A and Balzi E, Molecular cloning and characterization of a novel gene of Candida albicans, CDR1, conferring multiple resistance to drugs and antifungals. Curr Genet 27:320-329 (1995).

36 Alarco AM and Raymond M, The bZip transcription factor Cap $1 \mathrm{p}$ is involved in multidrug resistance and oxidative stress response in Candida albicans. F Bacteriol 181:700-708 (1999).

37 Vanden Bossche H, Dromer F, Improvisi I, Lozano Chiu M, Rex JH and Sanglard D, Antifungal drug resistance in pathogenic fungi. Med Mycol 36:119-128 (1998).

38 White TC, Marr KA and Bowden RA, Clinical, cellular, and molecular factors that contribute to antifungal drug resistance. Clin Microbiol Rev 11:382-402 (1998).

39 Anderson JB, Evolution of antifungal drug resistance: mechanisms and pathogen fitness. Nature Rev Microbiol 3:547-556 (2005).
40 White TC, The presence of an R467K amino acid substitution and loss of allelic variation correlate with an azoleresistant lanosterol 14alpha demethylase in Candida albicans. Antimicrob Agents Chemother 41:1488-1494 (1997).

41 Franz R, Kelly SL, Lamb DC, Kelly DE, Ruhnke $M$ and Morschhauser J, Multiple molecular mechanisms contribute to a stepwise development of fluconazole resistance in clinical Candida albicans strains. Antimicrob Agents Chemother 42:3065-3072 (1998).

42 Lyons CN and White TC, Transcriptional analyses of antifungal drug resistance in Candida albicans. Antimicrob Agents Chemother 44:2296-2303 (2000).

43 Schuetzer-Muehlbauer M, Willinger B, Krapf G, Enzinger S, Presterl E and Kuchler K, The Candida albicans Cdr2p ATPbinding cassette (ABC) transporter confers resistance to caspofungin. Mol Microbiol 48:225-235 (2003).

44 Leroux $\mathrm{P}$ and Fritz R, Antifungal activity of dicarboximides and aromatic hydrocarbons and resistance to these fungicides, in Mode of Action of Antifungal Agents, ed. by Trinci AP and Ryley JF. Cambridge University Press, Cambridge, pp. 207-237 (1984).

45 Leroux P, Chapeland F, Desbrosses D and Gredt M, Patterns of cross-resistance to fungicides in Botryotinia fuckeliana (Botrytis cinerea) isolates from French vineyards. Crop Protect 18:687-697 (1999).

46 Chapeland F, Fritz R, Lanen C, Gredt M and Leroux P, Inheritance and mechanisms of resistance to anilinopyrimidine fungicides in Botrytis cinerea (Botryotinia fuckeliana). Pestic Biochem Physiol 64:85-100 (1999).

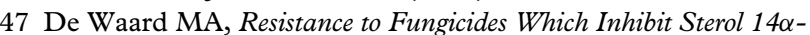
demethylation, a Historical Perspective (BCPC Monograph No. 60). BCPC, Farnham, pp. 3-10 (1994).

48 Delye C, Bousset L and Corio Costet MF, PCR cloning and detection of point mutations in the eburicol 14alphademethylase (CYP51) gene from Erysiphe graminis f. sp hordei, a 'recalcitrant' fungus. Curr Genet 34:399-403 (1998).

49 Stergiopoulos I, Van Nistelrooy JGM, Kema GHJ and De Waard MA, Multiple mechanisms account for variation in base-line sensitivity to azole fungicides in field isolates of Mycosphaerella graminicola. Pest Manag Sci 59:1333-1343 (2003).

50 Cools HJ, Fraaije B and Lucas JA, Molecular examination of Septoria tritici isolates with reduced sensitivity to triazoles, in Modern Fungicides and Antifungal Compounds IV, ed. by Dehne H-W, Gisi U, Kuck KH, Russel PE and Lyr H. BCPC, Alton, pp. 103-114 (2005).

51 Nakaune R, Adachi K, Nawata O, Tomiyama M, Akutsu K and Hibi T, A novel ATP-binding cassette transporter involved in multidrug resistance in the phytopathogenic fungus Penicillium digitatum. Appl Environ Microbiol 64:3983-3988 (1998).

52 Nakaune R, Hamamoto H, Imada J, Akutsu K and Hibi T, A novel ABC transporter gene, PMR5, is involved in multidrug resistance in the phytopathogenic fungus Penicillium digitatum. Mol Genet Genom 267:179-185 (2002).

53 Schepers HTAM, Changes during a three-year period in the sensitivity to ergosterol biosynthesis inhibitors of Sphaerotheca fuliginea. Neth F Plant Pathol 91:105-118 (1985).

54 Gisi U and Hermann D, Sensitivity behaviour of Septoria tritici populations on wheat to cyproconazole, in Fungicide Resistance, ed. by Heany S, Slawsun D, Holloman DW, Smith M, Russel PE and Parry DW, BCPC, Farnham, Surrey, UK. pp. 11-18 (1994).

55 Suty A and Kuck KH, Sensitivity of wheat leaf spot Septoria tritici to tebuconazole. Proc Br Crop Protection Conf-Pests and Diseases, Farnham, pp. 689-694 (1996).

56 Kalamarakis AE, De Waard MA, Ziogas BN and Georgopoulos SG, Resistance to fenarimol in Nectria haematococca var. cucurbitae. Pestic Biochem Physiol 40:212-220 (1991).

57 Van Tuyl JM, Genetics of fungal resistance to systemic fungicides. Meded Landbouwhogesch Wageningen 77:1-136 (1977). 
58 De Waard MA and Van Nistelrooy JGM, Stepwise development of laboratory resistance to DMI-fungicides in Penicillium italicum. Neth f Plant Pathol 96:321-329 (1990).

59 De Waard MA and Van Nistelrooy JGM, Accumulation of SBI fungicides in wild-type and fenarimol-resistant isolates of Penicillium italicum. Pestic Sci 22:371-382 (1988).

60 Köller W and Wilcox WF, Evidence for the predisposition of fungicide-resistant isolates of Venturia inaequalis to preferential selection for resistance to other fungicides. Phytopathology 91:776-781 (2001).

61 Gilpatrick JD and Blowers DR, Ascospore tolerance to dodine in relation to orchard control of apple scab. Phytopathology 64:649-652 (1974).

62 Yoder KS and Klos EJ, Tolerance to dodine in Venturia inaequalis. Phytopathology 66:918-923 (1976).

63 Kappas A and Georgopoulos SG, Genetic analysis of dodine resistance in Nectria haematococca. Genetics 66:617-622 (1970)

64 Wong FP and Wilcox WF, Sensitivity to azoxystrobin among isolates of Uncinula necator: baseline distribution and relationship to myclobutanil sensitivity. Plant Dis 86:394-404 (2002).

65 Fuchs A and De Waard MA, Resistance to ergosterolbiosynthesis inhibitors I. Chemistry and phenomenological aspects, in Fungicide Resistance in Crop Protection, ed. by Dekker J and Georgopoulos SG. Centre for Agricultural Publishing and Documentation, Wageningen, pp. 71-86 (1982).

66 Hamamoto H, Hasegawa K, Nakaune R, Lee YJ, Makizumi Y, Akutsu $\mathrm{K}$ and Hibi $\mathrm{T}$, Tandem repeat of a transcriptional enhancer upstream of the sterol 14alpha-demethylase gene (CYP51) in Penicillium digitatum. Appl Environ Microbiol 66:3421-3426 (2000)
67 Schnabel G and Jones AL, The 14alpha-demethylase (CYP51A1) gene is overexpressed in Venturia inaequalis strains resistant to myclobutanil. Phytopathology 91:102-110 (2001).

68 Schoustra S, Reducing fitness costs associated with antibiotic resistance. Experimental evolution in the filamentous fungus Aspergillus nidulans. Thesis, Wageningen University (2004).

69 Andrade AC, ABC transporters and multidrug resistance in Aspergillus nidulans. Thesis, Wageningen University (2000).

70 De Waard MA, Andrade AC, Braam C, Van Nistelrooy JGM, Swart K and Zwiers LH, Drug transporter mutants of Aspergillus nidulans as tools in fungicide discovery, in Modern Fungicides and Antifungal Compounds IV, ed. by Dehne $\mathrm{H}-$ W, Gisi U, Kuck KH, Russel PE and Lyr L. BCPC, Alton, pp. 13-20 (2005).

71 Avendano $\mathrm{C}$ and Menendez JC, Inhibitors of multidrug resistance to antitumor agents (MDR). Curr Med Chem 9:159-193 (2002).

72 De Waard MA and Van Nistelrooy JGM, Antagonistic and synergistic activities of various chemicals on the toxicity of fenarimol to Aspergillus nidulans. Pestic Sci 13:279-286 (1982).

73 De Waard MA and Van Nistelrooy JGM, Differential accumulation of fenarimol by a wild type isolate and fenarimol resistant isolates of Penicillium italicum. Neth F Plant Pathol 90:143-153 (1984).

74 Hayashi K, Schoonbeek H and De Waard MA, Modulators of membrane drug transporters potentiate the activity of the DMI fungicide oxpoconazole against Botrytis cinerea. Pest Manag Sci 59:294-302 (2003).

75 Reimann S and Deising HB, Inhibition of efflux transportermediated fungicide resistance in Pyrenophora tritici-repentis by a derivative of 4'-hydroxyflavone and enhancement of fungicide activity. Appl Environ Microbiol 71:3269-3275 (2005). 